\title{
Perfil metabólico e desenvolvimento da glândula mamária de novilhas leiteiras sob manejo para crescimento compensatório ${ }^{1}$
}

\author{
Patrícia Barcellos Costa ${ }^{2}$, Augusto César de Queiroz ${ }^{3}$, Marcelo Teixeira Rodrigues ${ }^{3}$, \\ André Luiz Rodrigues Magalhães ${ }^{2}$, Karina Zorzi ${ }^{2}$, Renius Mello², Márcia Maria Cândido da \\ Silva ${ }^{2}$, Nadja Gomes Alves ${ }^{2}$
}

\footnotetext{
1 Projeto financiado pelo Conselho Nacional de Desenvolvimento Científico e Tecnológico (CNPq).

2 Programa de Pós-graduação em Zootecnia - UFV - Viçosa, MG.

${ }^{3}$ Departamento de Zootecnia - UFV - Viçosa, MG.
}

RESUMO - Objetivou-se avaliar o efeito do manejo para crescimento compensatório e da suplementação com ionóforo sobre o perfil metabólico e o crescimento da glândula mamária de novilhas leiteiras. Foram utilizadas 20 novilhas Pardo-Suíças puras, com peso inicial de $200 \mathrm{~kg}$ e 5 meses de idade. Os tratamentos foram arranjados em esquema fatorial $2 \times 2$ e os animais foram alocados aleatoriamente em cada uma das combinações. O fator 1 consistiu dos sistemas de alimentação (convencional e crescimento compensatório) e o fator 2, da utilização ou não de ionóforo (200 mg de monensina/animal/dia). Os animais do sistema convencional receberam alimentação ad libitum, enquanto os do sistema para crescimento compensatório foram submetidos a um manejo nutricional com dois períodos distintos: período de restrição energética (90 dias, P1) e período de realimentação (60 dias, P2). Novilhas submetidas ao sistema crescimento compensatório apresentaram maior concentração de nitrogênio ureico (N-ureico) plasmático e menor razão DNA:RNA no tecido mamário. Quando analisados dentro de período, os níveis de lipoproteínas de alta densidade (HDL) aumentaram no período de realimentação, enquanto os de $\mathrm{N}$-ureico diminuíram. Além da alteração nos níveis de N-ureico, o balanço energético ao qual as novilhas em crescimento compensatório foram submetidas ocasionou aumento no teor dos ácidos graxos não-esterificados. Houve redução nos níveis de glicose sanguínea dos animais em crescimento compensatório no período de realimentação. A suplementação com ionóforo proporciona menor concentração de ácidos graxos não-esterificados durante o período de realimentação.

Palavras-chave: ionóforo, metabólitos sanguíneos, realimentação, restrição, vacas

\section{Metabolic profile and mammary gland development of dairy heifers under compensatory growth regime}

\begin{abstract}
The objective of this trial was to compare the effect of compensatory growth regime on the metabolic profile and mammary gland development of dairy heifers. Twenty Brown-Swiss heifers averaging $200 \mathrm{~kg}$ of body weight and five months of age were used in a completely randomized design with a $2 \times 2$ factorial arrangement. The treatments were arranged in a factorial arrangement $(2 \times 2)$ and the animals were randomly allocated in each one of the combinations. The factor 1 consisted of the feeding regime (conventional and compensatory growth) and the factor 2, of the use or not of ionophore (200 mg of monensin/animal/day). The animals in the conventional regime received ad libitum feeding, while those in the compensatory growth regime were submitted to a nutritional management with two different periods: period of energy restriction (90 days) and realimentation period (60 days). Heifers submitted to the compensatory growth regime showed larger concentration of plasma urea nitrogen and lower DNA:RNA ratio in the mammary gland. When period was analyzed, the levels of high density lipoprotein (HDL) increased in the realimentation period, while the urea $\mathrm{N}$ decreased. In addition to the alteration in the levels of urea $\mathrm{N}$, the energy balance to which the heifers in compensatory growth were submitted increased the non-esterified fatty acids. Blood glucose levels reduced in the animals in compensatory growth during the realimentation period. Supplementation with ionophore results in lower concentration of non-esterified fatty acids during the realimentation period.
\end{abstract}

Key Words: blood metabolites, cows, ionophore, realimentation, restriction

\section{Introdução}

A adequada nutrição na fase pré-púbere é fundamental para que novilhas leiteiras expressem todo o seu potencial genético para produção de leite. Isso ocorre porque há um período crítico no desenvolvimento mamário, chamado crescimento alométrico, em que o crescimento do tecido e o perfil metabólico são sensíveis ao manejo nutricional. 
Sinha \& Tucker (1969) observaram que o crescimento alométrico é mais acentuado em animais de 3 a 9 meses de idade (fase pré-púbere), pois, nesse período, a taxa de desenvolvimento do tecido mamário é 3,5 vezes mais rápida que a do tecido muscular.

Dietas com alta concentração energética podem reduzir o tecido secretório e aumentar o tecido adiposo na glândula mamária (Sejrsen et al., 1983; Shamay \& Gertler, 1986) dependendo do teor de proteína e, principalmente, da relação energia:proteína da dieta (Brian et al., 2002; Sexten et al., 2005). Segundo VanderHaar (1997), os efeitos negativos de dietas na fase pré-pubere sobre o desenvolvimento da glândula mamária ocorrem com maior frequência em experimentos onde as dietas apresentam baixa relação proteína bruta:energia metabolizável (PB:EM).

Uma vez que ocorram efeitos negativos, estes são atribuídos a alteração no número de células disponíveis para a síntese de leite (Tucker, 1981), desta forma a diminuição do tecido secretor resulta em menor produção e persistência de lactação (Knight et al., 1984). Park et al. (1988) e Choi et al. (1997) demonstraram que este efeito negativo poderia ser minimizado com a utilização do regime para ganho compensatório.

Pesquisas têm sido realizadas na tentativa de se desenvolver programas de alimentação e criação com ênfase no efeito da administração de dietas com alta concentração energética e do uso de produtos que elevam a taxa de gliconeogênese no fígado. No regime de nutrição compensatória, adota-se um esquema de manejo com a combinação de fases que alterna períodos de restrição energética e de realimentação. Com esse manejo, o desenvolvimento da glândula mamária é mínimo durante a fase de restrição energética, enquanto, no crescimento compensatório, induzido pela realimentação, ocorre desenvolvimento mais completo do tecido mamário (Ford \& Park, 2001).

Nesse contexto, objetivou-se avaliar o efeito do manejo para crescimento compensatório e da inclusão de monensina na dieta sobre o perfil metabólico e indicadores do número de células e da atividade de síntese proteica da glândula mamária de novilhas leiteiras.

\section{Material e Métodos}

O experimento foi conduzido no Departamento de Zootecnia do Centro de Ciências Agrárias da Universidade Federal de Viçosa (UFV), em Viçosa, MG. Foram utilizadas 20 novilhas Pardo-Suíças puras, com cinco meses de idade, peso inicial de $\pm 200 \mathrm{~kg}$ e peso adulto estimado de $500 \mathrm{~kg}$. O delineamento experimental utilizado foi o inteiramente casualizado, sendo os tratamentos arranjados em um esquema fatorial $(2 \times 2)$. $O$ fator 1 consistiu dos sistemas de alimentação (convencional e crescimento compensatório) e o fator 2, da utilização ou não de ionóforo (200 mg de monensina/animal/dia). Os animais do sistema convencional receberam alimentação ad libitum, com dieta formulada para atender às recomendações nutricionais propostas pelo NRC (2001) para ganhos de peso de 800g/dia durante todo o período experimental. As novilhas do sistema de crescimento compensatório, no entanto, foram submetidas a um manejo nutricional, com dois períodos distintos: no primeiro período ( $\mathrm{P} 1$, período restrição, 90 dias) o consumo de matéria seca (CMS) foi limitado a 2,5\% do peso corporal (PC) e a dieta continha $25 \%$ menos energia metabolizável (EM) que a dieta do sistema convencional, enquanto, no segundo período (P2, período realimentação, 60 dias) a oferta de MS e de EM da dieta não diferiu do grupo em sistema convencional (Tabela 1).

Tabela 1 - Composição das dietas experimentais

\begin{tabular}{|c|c|c|c|c|}
\hline \multirow[t]{2}{*}{ Alimento } & \multicolumn{4}{|c|}{ Sistema de alimentação } \\
\hline & Sem ionóforo & Com ionóforo & Sem ionóforo & Com ionóforo \\
\hline & \multicolumn{4}{|c|}{ Primeiro período } \\
\hline Feno de capim-tifton 85 & 60,00 & 60,00 & 60,00 & 60,00 \\
\hline Milho grão moído & 15,31 & 15,31 & 2,10 & 2,10 \\
\hline \multirow[t]{2}{*}{ Mistura mineral $^{1}$} & 0,80 & 0,80 & 0,70 & 0,70 \\
\hline & \multicolumn{4}{|c|}{ Segundo período } \\
\hline Feno tifton 85 & 60,00 & 60,00 & 50,00 & 50,00 \\
\hline Milho grão moído & 15,10 & 15,10 & 20,10 & 20,10 \\
\hline Farelo de algodão & 23,50 & 23,50 & 28,50 & 28,50 \\
\hline Calcário calcítico & 0,60 & 0,60 & 0,60 & 0,60 \\
\hline
\end{tabular}

${ }^{1}$ Composição percentual: $14 \%$ de cálcio; $9 \%$ de fósforo; 2,5\% de enxofre; 2,5\% de magnésio; 0,55\% de zinco; 0,15\% de cobre. 
A duração do período experimental foi de 180 dias, sendo os 30 primeiros destinados à adaptação dos animais. Os animais foram alojados em baias individuais, com piso de cimento, cobertas parcialmente com telhas do tipo amianto, onde tiveram acesso permanente ao alimento e à água. A alimentação foi oferecida duas vezes ao dia, às 7 e $17 \mathrm{~h}$, permitindo-se sobras de, no máximo, $10 \%$ para os sistemas convencional e de crescimento compensatório no período de realimentação. A dieta foi calculada para que todos os animais, independentemente do tratamento, recebessem a mesma quantidade de $\mathrm{PB}$ em todos os períodos, desta forma a relação PB:EM da dieta não foi a mesma para os tratamentos testados (Tabela 2).

Diariamente, para estimativa do consumo, foram registradas as quantidades dos alimentos fornecidos e das sobras, sendo elaboradas amostras compostas da dieta e das sobras, por animal e por período para análises posteriores. Nos alimentos foram determinadas as concentrações de matéria seca (MS), nitrogênio total, extrato etéreo, cinzas (CZ), cálcio e fósforo utilizando-se as técnicas descritas por Silva \& Queiroz (2002); de fibra em detergente neutro (FDN), segundo Van Soest et al. (1991); de fibra em detergente ácido (FDA), conforme método da AOAC (1990); nitrogênio insolúvel em detergente neutro (NIDN) e nitrogênio insolúvel em detergente ácido (NIDA), conforme técnicas descritas por Licitra et al. (1996); e de lignina em ácido sulfúrico, de acordo com técnica descrita por Pereira \& Rossi Junior (1995). As sobras foram analisadas para determinação dos teores de matéria seca, nitrogênio total, extrato etéreo, cinzas e FDN.

Os teores de carboidratos não-fibrosos (CNF) foram obtidos a partir da equação: $\mathrm{CNF}=100-(\% \mathrm{~PB}+\% \mathrm{EE}+\% \mathrm{CZ}$ + \%FDNcp), segundo Sniffen et al. (1992).

A concentração de energia dos alimentos foi estimada segundo Van Soest (1994), utilizando-se a equação: NDT = DMS - cinzas +1,25 $\times(E E)+1,9$, em que DMS éa digestibilidade da matéria seca, obtida como: DMS $=(100-$ FDN $) * 0,98+$ (FDN*DFDN/100)-12,8. DFDN é a digestibilidade estimada da FDN, calculada como: DFDN = 147,3-78,9 $\log _{10}$ [(LDA/ FDA)*100], em que LDA representa o conteúdo de lignina do alimento. A conversão dos valores de NDT para energia metabolizável (EM) foi realizada por meio da equação: EM $(\mathrm{Mcal} / \mathrm{kg})=1,01 \times \mathrm{ED}(\mathrm{Mcal} / \mathrm{kg})-0,45$, em que ED é o teor de energia digestível, obtido como: $\mathrm{ED}(\mathrm{Mcal} / \mathrm{kg})=0,04409 \times \mathrm{NDT}$ (\%). Ambas as equações foram propostas pelo NRC (2001).

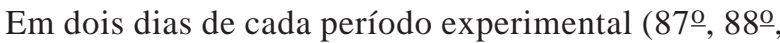

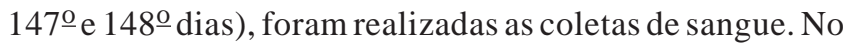
dia anterior às coletas, um cateter endovenoso central,

Tabela 2 - Composição química das dietas experimentais

\begin{tabular}{|c|c|c|c|c|}
\hline \multirow[t]{3}{*}{ Item } & \multicolumn{4}{|c|}{ Sistema de alimentação } \\
\hline & \multicolumn{2}{|c|}{ Convencional } & \multicolumn{2}{|c|}{ Crescimento compensatório } \\
\hline & Sem ionóforo & Com ionóforo & Sem ionóforo & Com ionóforo \\
\hline Matéria seca $(\mathrm{g} / \mathrm{kg})$ & 853,70 & 853,70 & 856,70 & 856,70 \\
\hline Matéria orgânica (g/kg) & 937,20 & 937,20 & 927,50 & 927,50 \\
\hline Proteína bruta (g/kg) & 175,00 & 175,00 & 212,90 & 212,90 \\
\hline Carboidratos totais $(\mathrm{g} / \mathrm{kg})$ & 747,20 & 747,20 & 702,30 & 702,30 \\
\hline Carboidratos não-fibrosos (g/kg) & 228,20 & 228,20 & 174,10 & 174,10 \\
\hline Fibra em detergente neutro (g/kg) & 572,00 & 572,00 & 581,20 & 581,20 \\
\hline Cálcio (g/kg) & 5,40 & 5,40 & 6,20 & 6,20 \\
\hline Fósforo (g/kg) & 3,90 & 3,90 & 5,00 & 5,00 \\
\hline Energia metabolizável, $\mathrm{EM}_{3 \mathrm{x}}(\mathrm{Mcal} / \mathrm{kg})$ & 2,34 & 2,34 & 2,28 & 2,28 \\
\hline Proteína bruta $(\mathrm{g} / \mathrm{kg})$ & 175,70 & 175,70 & 186,50 & 186,50 \\
\hline Nitrogênio insolúvel em detergente neutro (g/100 g NT) & 41,79 & 41,79 & 36,39 & 36,39 \\
\hline Extrato etéreo (g/kg) & 14,90 & 14,90 & 16,30 & 16,30 \\
\hline Carboidratos totais $(\mathrm{g} / \mathrm{kg})$ & 746,50 & 746,50 & 735,70 & 735,70 \\
\hline Carboidratos não-fibrosos (g/kg) & 227,40 & 227,40 & 267,70 & 267,70 \\
\hline Fibra em detergente neutro, FDN (g/kg) & 572,20 & 572,20 & 512,20 & 512,20 \\
\hline Cálcio (g/kg) & 5,40 & 5,40 & 5,90 & 5,90 \\
\hline Fósforo (g/kg) & 3,90 & 3,90 & 3,80 & 3,80 \\
\hline Energia metabolizável, EM EMx $_{1,5}$ (Mcal/kg) & 2,31 & 2,31 & 2,42 & 2,42 \\
\hline Nutrientes digestíveis totais, $\mathrm{NDT}_{1,5 \mathrm{x}}(\mathrm{g} / \mathrm{kg})$ & 593,00 & 593,00 & 615,80 & 615,80 \\
\hline
\end{tabular}


flexível, com $17 \mathrm{~mm} \times 20,3 \mathrm{~cm}$, foi inserido na veia jugular dos animais. No primeiro dia de coleta, amostras de $10 \mathrm{~mL}$ de sangue foram coletadas em intervalos de 30 minutos, durante 5 horas, sendo a primeira coleta realizada 1 hora após a alimentação. As amostras foram mantidas em temperatura ambiente durante 1 hora para permitir a formação do coágulo e, em seguida, efetuou-se a centrifugação do material, para obtenção do soro, que foi armazenado a $-20{ }^{\circ} \mathrm{C}$, para análises dos níveis de triiodotironina circulante total (T3). A concentração de T3 foi quantificada por meio de automação utilizando-se imunoensaio competitivo de fase sólida, de enzimas químico-luminosas. A coleta realizada 4 horas após a alimentação foi utilizada para quantificação da concentração de N-ureico, por meio de análise colorimétrica (kit comercial). No segundo dia, a coleta foi realizada após 14 horas de jejum e as amostras obtidas foram armazenadas para análises colorimétricas, para determinação dos teores de ácidos graxos não-esterificados (AGNE), glicose, colesterol total e lipoproteínas de alta densidade (HDL).

No último dia do período experimental (150음ia), foi realizada biópsia da glândula mamária das novilhas que estavam na fase luteal do ciclo estral, para retirada de $15 \mathrm{~g}$ de tecido, por meio de cortes de $4 \mathrm{~cm}$ no quarto mamário esquerdo, como descrito por Choi et al. (1988). O tecido foi armazenado em RNA later e congelado a $-20^{\circ} \mathrm{C}$, para quantificação de RNA e DNA total. A extração de RNA e DNA foi realizada por meio do método do reagente trizol, proposto por Chomoczynski \& Sacchi (1987).

Os dados de AGNE, glicose, colesterol total, HDL e Nureico foram submetidos à análise de variância, por meio de modelos contendo os efeitos de sistema, ionóforo e período, além das interações entre essas fontes de variação (efeitos fixos) e do resíduo (efeito aleatório), utilizando-se o PROC GLM do Statistical Analysis System (versão 8.12). Para as variáveis RNA, DNA e DNA:RNA, os modelos continham apenas os efeitos de sistema e ionóforo, as interações e o resíduo. Quando necessário e na presença de efeitos significativos das interações, os efeitos de sistema e ionóforo foram analisados dentro de cada período. As diferenças entre as fontes de variação foram estimadas aplicando-se o teste t de Student. Para a variável T3, foi realizada análise de regressão, considerando-se todos os dados em conjunto, bem como para cada sistema de alimentação, utilizando-se modelos quadráticos.

\section{Resultados e Discussão}

Diferentemente do esperado, não houve efeitos significativos das interações sistema de alimentação $\times$ período, mesmo com diferentes relações proteína:energia nas dietas, nos períodos de restrição (P1; PB:EM = 75 g/Mcal) e de realimentação (P2; PB:EM = 93g/Mcal), oferecidas aos animais em crescimento compensatório. A alteração da energia digestível das dietas pode influenciar o crescimento microbiano, em função da variação na disponibilidade de substratos (Clark et al., 1992) como carboidratos, amônia, peptídeos, aminoácidos, enxofre e ácidos graxos de cadeia ramificada (Sniffen et al., 1993) e por outros fatores, como a taxa de passagem, $\mathrm{pH}$, taxa de fermentação e predação dentro do rúmen (Merchen, 1988; Van Soest, 1994). A inexistência de efeitos significativos das interações sistema de alimentação $\times$ período deve ter ocorrido pelos altos valores em comparação ao preditos pelo NRC (2001) e pela relação PB:EM utilizada nos períodos experimentais, que não limitaram a síntese de proteína microbiana.

Quando comparadas aos animais do sistema convencional, as novilhas submetidas ao sistema de crescimento compensatório apresentaram maior $(\mathrm{P}<0,01)$ concentração de N-ureico no plasma (Tabela 3). Desse modo, a alta concentração de N-ureico no plasma foi indicativo de excesso de amônia no rúmen e pode ter resultado do consumo de proteínas dietéticas de rápida degradação ruminal e de rações com baixa relação energia:proteína (Park, 1985), como a dieta oferecida no período de restrição para as novilhas em crescimento compensatório. O teor de N-ureico plasmático está estreitamente relacionado ao metabolismo de nitrogênio (N). Quando a taxa de degradação proteica ruminal excede a de síntese microbiana, o excesso de amônia produzido é absorvido pela parede do rúmen e segue pela corrente sanguínea até o fígado, onde ocorre a conversão de amônia em ureia, que, posteriormente, é excretada na urina, no leite e no fluido uterino (Roseler et al., 1993).

Quando analisado dentro de período, os níveis de HDL (mg/dL) aumentaram no período 2, enquanto o N-ureico diminuiu. Durante os primeiros 90 dias do período experimental, os animais em crescimento compensatório foram submetidos à restrição energética (dieta com 30\% menos energia que a do sistema de alimentação convencional) e, por isso, não tiveram disponibilidade de carboidratos na dieta em quantidade suficiente para a síntese de proteína microbiana e para sua conversão em energia, o que resultou em elevação do teor de $\mathrm{N}$-ureico plasmático e redução da concentração de HDL (Tabela 3). Da mesma forma, Park et al. (1987) verificaram aumento na concentração de HDL em novilhas em ganho compensatório, o que é benéfico para a saúde animal, uma vez que o maior nível de HDL circulante impede o acúmulo de triglicérides no fígado. 
Quanto à ausência de efeito dos ionóforos sobre a concentração de N-ureico, Dugmore (1992) sugeriu que a monensina pode reduzir a excessiva quebra de proteína no rúmen e, consequentemente, a excreção de $\mathrm{N}$-ureico sanguíneo. Uma vez que o efeito desse antibiótico sobre o teor de N-ureico depende da degradabilidade protéica dos alimentos utilizados na dieta, animais em pastejo podem apresentar diminuição na excreção de nitrogênio plasmático, que pode não ser evidente em animais alimentados com dieta à base de feno, como neste experimento. Van der Merwe (2001) observou que animais em pastejo consumindo dieta suplementada com monensina apresentaram teor de N-ureico em média 9,77\% inferior ao do grupo controle. A ausência de efeito da monensina sobre o teor plasmático de ureia neste estudo corrobora os resultados obtidos por Stephenson et al. (1997) e Duffield et al. (2001), sugerindo que os efeitos da monensina sobre o metabolismo proteico foram inferiores ao efeito sobre a disponibilidade de glicose. Segundo Stephenson et al. (1997), o aumento na disponibilidade proteica proporcionado pela suplementação com ionóforo pode ser pequeno ou a estimativa do teor plasmático de ureia pode não ser suficientemente sensível para detectar diferenças no metabolismo proteico.

Além da alteração nos níveis de N-ureico, o balanço energético (no período de restrição) ao qual as novilhas no sistema de crescimento compensatório foram submetidas provocou aumento $(\mathrm{P}<0,01)$ na concentração plasmática de ácidos graxos não-esterificados. O teor plasmático de glicose foi mais baixo nos animais em crescimento compensatório no período de realimentação que naqueles do sistema convencional (Tabela 4). O aumento no fluxo de precursores glicogênicos, proporcionado pela dieta utilizada no período de realimentação com relação volumoso:concentrado 50:50, pode ter estimulado a liberação de insulina e resultado em menor concentração plasmática de glicose (Stephenson et al., 1997), ocasionando aumento no fluxo desse metabólito para atender à demanda de nutrientes para o crescimento corporal (Arieli et al., 2001).

Entre as variáveis de perfil metabólico estudadas, a suplementação com ionóforo à dieta influenciou apenas os teores de AGNE, que tiveram sua concentração reduzida $(\mathrm{P}<0,05)$ durante o período de realimentação. Os ionóforos

Tabela 3 - Metabólitos sanguíneos em novilhas de diversos sistemas de alimentação com ou sem ionóforo na dieta

\begin{tabular}{|c|c|c|c|c|}
\hline \multirow[t]{2}{*}{ Item } & \multicolumn{3}{|c|}{ Sistema de alimentação } & \multirow[t]{2}{*}{ Valor $\mathrm{P}^{1}$} \\
\hline & Convencional & Crescimento compensatório & $\begin{array}{c}\text { Convencional-Crescimento } \\
\text { compensatório }\end{array}$ & \\
\hline HDL (mg/dL) & 49,13 & 52,22 & $-3,09 \pm 4,86$ & 0,5287 \\
\hline Colesterol total (mg/dL) & 81,28 & 82,74 & $-1,46 \pm 6,19$ & 0,8148 \\
\hline \multirow[t]{2}{*}{ N-ureico (mg/dL) } & 23,61 & 27,27 & $-3,66 \pm 0,96$ & 0,0006 \\
\hline & Sem ionóforo & $\begin{array}{l}\text { Ionóforo } \\
\text { Com ionóforo }\end{array}$ & Sem ionóforo-Com ionóforo & \\
\hline HDL (mg/dL) & 48,06 & 53,3 & $-5,23 \pm 4,86$ & 0,2900 \\
\hline Colesterol total (mg/dL) & 79,28 & 84,74 & $-5,46 \pm 6,19$ & 0,3847 \\
\hline \multirow[t]{2}{*}{ N-ureico (mg/dL) } & 26,17 & 24,71 & $1,46 \pm 0,96$ & 0,1393 \\
\hline & Período 1 (P1) & $\begin{array}{c}\text { Período } \\
\text { Período } 2 \text { (P2) }\end{array}$ & Período 1-Período 2 & \\
\hline HDL (mg/dL) & 43,33 & 58,02 & $-14,69 \pm 4,86$ & 0,0049 \\
\hline Colesterol total (mg/dL) & 79,02 & 85 & $-5,98 \pm 6,19$ & 0,3415 \\
\hline$\underline{\text { N-ureico }(\mathrm{mg} / \mathrm{dL})}$ & 28,06 & 22,82 & $5,24 \pm 0,96$ & $<0,0001$ \\
\hline
\end{tabular}

${ }^{1}$ Valor de P pelo teste $t$ de Student.

Tabela 4 - Metabólitos sanguíneos nos primeiros 90 dias (período 1) e últimos 60 dias (período 2) experimentais de novilhas em diversos sistemas de alimentação com ou sem ionóforo na dieta

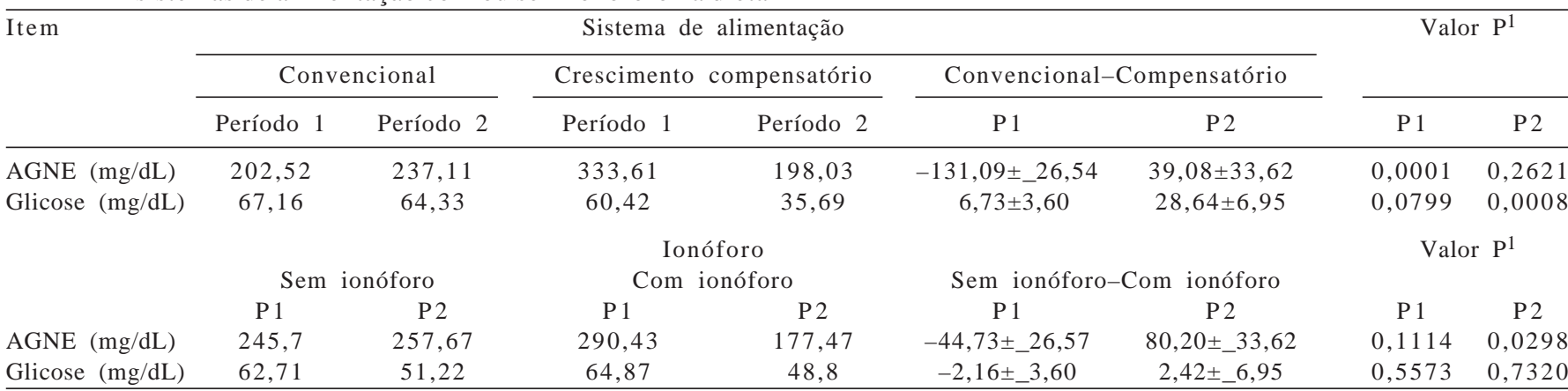

${ }^{1}$ Valor de $\mathrm{P}$ pelo teste t de Student. 
alteram a fermentação ruminal, aumentando a formação de propionato e a oxidação hepática de glicose no ciclo do ácido tricarboxílico e reduzindo a relação acetato:propionato (Richardson et al., 1976) e a produção ruminal de butirato (Shell et al., 1983). Esses fatores, em conjunto, proporcionam aumento na disponibilidade de energia para o crescimento animal e, consequentemente, reduzem a utilização das reservas corporais (Arieli et al., 2001; Ignácio et al., 2003). Os resultados encontrados neste experimento confirmam as mudanças nos metabólicos sanguíneos observadas em outros estudos (Arieli et al., 2001; Stephenson et al., 1997; Abe et al., 1994). Como neste trabalho, Stephenson et al. (1997) não verificaram diferença no teor sanguíneo de glicose entre os animais tratados e os não-tratados com monensina. Arieli et al. (2001) sugeriram que os antibióticos carboxílicos podem aumentar a gliconeogênese sem alterar o teor de glicose sanguínea, por estímulo na liberação de insulina, fazendo com que a glicose seja utilizada para manutenção e crescimento corporal. Além disso, a alta demanda de glicose para o crescimento corporal pode tornar a concentração deste metabólito constante.

A concentração de RNA no tecido mamário (mg por g de tecido) foi maior nos animais que receberam ionóforo na alimentação e a razão DNA:RNA foi inferior nas novilhas em crescimento compensatório (Tabela 5). Similarmente, Guereiro et al. (2005) verificaram que borregas submetidas a diferentes níveis nutricionais apresentaram menor proporção DNA:RNA no tecido mamário quando submetidas a níveis nutricionais altos. $\mathrm{O}$ aumento na concentração de RNA tecidual pode refletir em incremento na produção de leite. Park et al. (1989), em estudo envolvendo quatro ciclos de lactação, comprovaram que animais em regime de ganho compensatório produzem $10 \%$ mais leite que aqueles criados em sistema convencional, o que representa aproximadamente $900 \mathrm{~kg}$ de leite em 250 dias. Esses autores concluíram que o ganho compensatório induzido durante a realimentação pode alterar o nível e a atividade dos fatores que regulam a proliferação celular como resultado das mudanças no status hormonal do animal.

A quantificação do DNA e RNA pode ser utilizada como indicativo do número de células e da atividade de síntese proteica. Embora a determinação do DNA não permita a quantificação de classes individuais de células e, consequentemente, do número de células secretoras, a concentração de DNA e de RNA e a razão RNA:DNA podem ser utilizadas como parâmetro do desenvolvimento da glândula mamária (Tucker, 1981; Park et al., 1989).

Não foi verificado efeito significativo para o nível plasmático de T3, mesmo conhecendo-se sua ação secundária sobre a mamogênese pela produção de mudanças metabólicas favoráveis para o desenvolvimento do tecido mamário. A inexistência de efeito sobre os valores de T3 pode estar relacionada à variação dentro de cada hora maior que a variação entre horas. Portanto, sugere-se que, como alternativa para a avaliação desta variável, seja utilizado maior número de repetições para cada tempo com vistas à redução da variabilidade dos dados.

Tabela 5 - Desenvolvimento da glândula mamária em novilhas de diversos sistemas de alimentação com ou sem ionóforo na dieta

\begin{tabular}{|c|c|c|c|c|}
\hline \multirow[t]{2}{*}{ Item } & \multicolumn{3}{|c|}{ Sistema de alimentação } & \multirow[t]{2}{*}{ Valor $\mathrm{P}^{1}$} \\
\hline & Convencional & Crescimento compensatório & $\begin{array}{c}\text { Convencional-Crescimento } \\
\text { compensatório }\end{array}$ & \\
\hline RNA $(\mu \mathrm{g} / \mathrm{mL})$ & 63,59 & 71,04 & $-7,45 \pm 5,18$ & 0,1785 \\
\hline DNA $(\mu \mathrm{g} / \mathrm{mL})$ & 80,43 & 73,48 & $6,95 \pm 3,96$ & 0,1074 \\
\hline RNA (mg/g de tecido mamário) & 0,74 & 0,8 & $-0,05 \pm 0,09$ & 0,5618 \\
\hline DNA (mg/g de tecido mamário) & 0,91 & 0,83 & $0,09 \pm 0,09$ & 0,3750 \\
\hline \multirow[t]{2}{*}{ DNA:RNA } & 1,33 & 1,03 & $0,30 \pm 0,14$ & 0,0580 \\
\hline & Sem ionóforo & $\begin{array}{c}\text { Ionóforo } \\
\text { Com ionóforo }\end{array}$ & Sem ionóforo-Com ionóforo & \\
\hline RNA $(\mu \mathrm{g} / \mathrm{mL})$ & 64,41 & 70,22 & $-5,81 \pm 5,18$ & 0,2861 \\
\hline DNA $(\mu \mathrm{g} / \mathrm{mL})$ & 80,18 & 73,73 & $6,45 \pm 3,96$ & 0,1321 \\
\hline RNA (mg/g de tecido mamário) & 0,64 & 0,89 & $-0,25 \pm 0,09$ & 0,0167 \\
\hline DNA (mg/g de tecido mamário) & 0,81 & 0,93 & $-0,12 \pm 0,09$ & 0,2440 \\
\hline DNA:RNA & 1,31 & 1,06 & $0,25 \pm 0,14$ & 0,0983 \\
\hline
\end{tabular}

${ }^{1}$ Valor de P pelo teste $t$ de Student.

\section{Conclusões}

Novilhas leiteiras submetidas ao manejo nutricional para crescimento compensatório durante o período de realimentação apresentam modificações na concentração de metabólitos. O manejo para crescimento compensatório e a utilização de monensina podem ser adotados com o objetivo de aumentar a atividade de síntese proteica no tecido mamário. 


\section{Referências}

ABE, N.; LEAN, J.J.; RABIEE, A. et al. Effects of sodium monensin on reproductive performance of dairy cattle. II. Effects on metabolites in plasma, resumption of ovarian cyclicity and oestrus in lactating cows. Australian Veterinary, v.71, p.277-282, 1994.

ASSOCIATION OF OFFICIAL ANALYTICAL CHEMISTRY AOAC. Official methods of analysis. 15.ed. Arlington: AOAC International, 1990. 1117p.

ARIELI, A.; VALLIMONT, J.E.; AHARONI, Y. et al. Monensin and growth effects on glucose metabolism in the prepartum cow. Journal of Dairy Science, v.84, p.2770-2776, 2001.

BRIAN, K.W.; WHITLICK, M.J.; VANDEHAAR, L.F. et al. Effect of dietary protein on prepubertal mammary development in rapidly growing dairy heifers. Journal of Dairy Science, v.85, p.1516-1525, 2002.

CHOI, Y.J.; KELLER, W.L.; BERG, I.E. et al. Casein gene expression in bovine mammary gland. Journal of Dairy Science, v.71, p.2898-2903, 1988.

CHOI, Y.J.; HAN, K.I.; WOO, H.J. et al. Compensatory growth in dairy heifers: The effect of a compensatory growth pattern on growth rate in lactation performance. Journal of Dairy Science, v.80, p.519-524, 1997.

CHOMOCZYNSKI, P.; SACCHI, N. Single-step method of RNA isolation by acid guanidinium thiocyanate-phenol-cloroform extration. Analytical Biochemistry, v.162, p.1-50, 1987.

CLARK, J.H.; KLUSMEYER, T.H.; CAMERON, M.R. Microbial protein synthesis and flows of nitrogen fractions to the duodenum of dairy cows. Journal of Dairy Science, v.75, p.2304-2323, 1992.

DUFFIELD, T.F.; SANDALS, D.; LESLIE, K.E. et al. Effect of prepartum administration of monensin in a controlled-release capsule on postpartum energy indicators in lactating dairy cows. Journal of Dairy Science, v.81, p.2354-2361, 2001.

DUGMORE, T.J. Study tour report: dairying in Australia and New Zealand. Report Cedara Agricultural Development Institute, v.1, p.1-15, 1992.

FORD, A.J.; PARK, C.S. Nutritionally directed compensatory growth enhances heifer development and lactation potential. Journal of Dairy Science, v.84, p.1669-1678, 2001.

GUEREIRO, C.D.; BELO, A.T.; PEREIRA, M.S. et al. Efeito do nível nutricional no desenvolvimento da glândula mamária em borregas da raça Serra da Estrela. Revista Portuguesa de Ciências Veterinárias, v.100, p.53-60, 2005

IGNÁCIO, R.I.; CLARK, J.H. Usefulness of ionophores for lactating dairy cows: a review. Animal Feed Science and Technology, v.106, p.39-57, 2003.

KNIGHT, C.H.; DOCHERTY, A.H.; PEAKER, M. Milk yield in rats in relation to activity and size of mammary secretory cell population. Journal of Dairy Research, v.51, p.29-35, 1984.

LICITRA, G.; HERNÁNDEZ, T.M.; VAN SOEST, P.J. Standardization of procedures for nitrogen fractionation of ruminant feeds. Animal Feed Science and Technology, v.57, p.347-358, 1996.

MERCHEN, N.R. Digestion, absorption and excretion in ruminants. In: CHURCH, D.C. (Ed.) The ruminant animal: digestive physiology and nutrition. 2.ed. Prentice Hall: Englewood cliffs, 1988. p.172-201.

NATIONAL RESEARCH COUNCIL - NRC. Nutrient requirement of dairy cattle. 7.ed. Washington: National Academy Press, 2001. 381p.

PARK, C.S. Influence of dietary protein on blood cholesterol and related metabolites of growing calves. Journal of Animal Science, v.61, p.924-930, 1985.

PARK, C.S.; ERICKSON, G.M.; CHOI, Y.J. et al. Effect of compensatory growth on regulation of growth and lactation: response of dairy heifers to a stair-step growth pattern. Journal of Animal Science, v.64, p.1751-1758, 1987.

PARK, S.C.; BAIK, M.G.; KELLER, W.L. et al. Role of compensatory growth in lactation: a stair-step nutrient regimen modulates differentiation and lactation of bovine mammary gland. Growth Development Aging, v.53, p.159-166, 1989.

PARK, S.C.; CHOI, Y.J.; KELLER, W.L. et al. Effects of compensatory growth on milk protein gene expression and mammary differentiation. Journal FASEB, v.2, p.2619-2624, 1988.

PEREIRA, J.R.A.; ROSSI JUNIOR, P. Manual prático de avaliação de alimentos. Piracicaba: Fundação de Estudos Agrários Luiz de Queiroz, 1995. 25p.

RICHARDSON, L.F.; RAUN, A.P.; POTTER, E.L. et al. Effect of monensin on rumen fermentation in vitro and in vivo. Journal of Animal Science, v.43, p.657-670, 1976.

ROSELER, D.K.; FERGUSON, J.D.; SNIFFEN, C.J. et al. Dietary protein degradability effects on plasma and milk urea nitrogen and milk nonprotein nitrogen in Holstein cows. Journal of Dairy Science, v.76, p.525-534, 1993.

SEJRSEN, K.; HUBER, J.T.; TUCKER, H.A. Influence of amount fed on hormone concentrations and their relationship to mammary growth in heifers. Journal Dairy Science, v.69, p. 845-855, 1983.

SEXTEN, W.J.; FAULKNER, D.B.; DAHLQUIST, J.M. et al. Influence of creep feeding and protein level on growth and maternal performance of replacement beef heifers. Animal Science, v.20, p.2110-217, 2004

SHAMAY, A.; GERTLER, A. A model for in vitro proliferation of undifferentiated bovine mammary epithelial cells. Cell Biology International Report, v.10, p.923-929, 1986.

SHELL, L.A.; HALE, W.H.; THEURER, B. et al. Effects of monensin on total volatile fatty acid production by steers fed a high grain diet. Journal of Animal Science, v.57, p.178-185, 1983.

SILVA, D.J.; QUEIROZ, A.C. Análises de alimentos: métodos químicos e biológicos. 3.ed. Viçosa, MG: UFV, 2002. 235p.

SINHA, Y.N.; TUCKER, H.A. Mammary development and pituitary prolactin level of heifers from birth through puberty and during the estrous cycle. Journal of Dairy Science, v.52, p.507-512, 1969.

SNIFFEN, C.J.; BEVERLY, R.W.; MOONEY, C.S. et al. Nutrient requirements versus supply in the dairy cow: strategies to account for variability. Journal of Dairy Science, v.76, p.3160-3178, 1993.

SNIFFEN, C.J.; O'CONNOR, D.J.; VAN SOEST, P.J. et al. A net carbohydrate and protein system for evaluating cattle diets: Carbohydrate e protein availability. Journal of Animal Science, v.70, p.3562-3577, 1992.

STEPHENSON, K.A.; LEAN, I.J.; HYDE, M.L. et al. Effects of sodium monensin on the metabolism of periparturient dairy cows. Journal of Dairy Science, v.80, p.830-837, 1997.

TUCKER, H.A. Physiological control of mammary growth, lactogenesis, and lactation. Journal of Dairy Science, v.64 p.1403-1421, 1981.

VAN DER MERWE, B.J.; DUGMORE, T.J.; WALSH, K.P. The effect of monensin on milk production, milk urea nitrogen and body condition score of grazing dairy cows. South African Journal of Animal Science, v.31, p.49-55, 2001.

VAN SOEST, P.J. Nutritional ecology of the ruminant. Ithaca: Cornell University Press, 1994. 476p.

VANDEHAARS, M.J. Dietary protein and mammary development of heifers: analysis from literature data. Journal of Dairy Science, v. 80 , p.216, 1997.

VAN SOEST, P.J.; ROBERTSON, J.B.; LEWIS, B.A. Methods of dietary fiber, neutral detergent fiber, and nonstarch polysaccharides in relation to animal nutrition. Journal of Animal Science, v.74, p.3583-3597, 1991. 